\title{
USO DE EQUAÇÕES PARA ESTIMAR CARBONO ORGÂNICO EM PLANTAÇÕES DE Acacia mearnsii DE WILD. NO RIO GRANDE DO SUL -BRASIL ${ }^{1}$
}

\begin{abstract}
Fabio Luiz Fleig Saidelles ${ }^{2}$, Marcos Vinicius Winckler Caldeira ${ }^{3}$, Mauro Valdir Schumacher ${ }^{4}$ e Rafaelo Balbinot ${ }^{5}$
RESUMO - Para entender a importância das florestas e plantações florestais como sumidouros de carbono, é necessário desenvolver e aprimorar as metodologias de estimativa de biomassa e carbono. Assim, o objetivo deste trabalho foi estimar o estoque de carbono orgânico (CO) em plantações de Acacia mearnsii com 4 anos de idade. A área de trabalho localiza-se na cidade de Arroio dos Ratos, RS, nas coordenadas $30^{\circ} 07^{\prime} 12^{\prime \prime}$ de latitude sul e $51^{\circ} 57^{\prime} 45^{\prime \prime}$ de longitude oeste, com altitude média de $90 \mathrm{~m}$. Após a realização de inventário florestal, foram abatidas 21 árvores, distribuídas em sete classes diamétricas, para cobrir a heterogeneidade do povoamento. Em seguida, determinaram-se a biomassa e o teor de $\mathrm{CO}$ dos componentes: folha, galho vivo, galho morto, madeira, casca e raiz. A estimativa do estoque de $\mathrm{CO}$ em povoamentos de Acacia mearnssi e nos seus compartimentos das árvores pode ser realizada por meio de equações matemáticas. O total de CO estocado na biomassa é de $29,79 \mathrm{Mg} \mathrm{ha}^{-1}$, distribuídos da seguinte forma: $64 \%$ na madeira, $11 \%$ na raiz, $9 \%$ na casca, $7 \%$ nos galhos vivos e $4 \%$ nos galhos mortos e nas folhas.
\end{abstract}

Palavras-chave: Acácia-negra, plantações florestais e biomassa.

\section{USE OF EQUATIONS TO ESTIMATE ORGANIC CARBON IN Acacia mearnsii DE WILD PLANTATIONS IN RIO GRANDE DO SUL - BRAZIL}

\begin{abstract}
To understand the importance of the forests and forest plantations as carbon sink, it is necessary to develop and improve the methodologies to estimate biomass and carbon. The aim of this study was to estimate the organic carbon $(O C)$ stock in 4-year-old plantations of Acacia mearnsii. The work area is located in Arroio dos Ratos-RS, in a farm of the Agroseta S.A. corporation, with coordinates $30^{\circ} 07^{\prime} 12^{\prime \prime}$ latitude south and 51 $57^{\prime} 45^{\prime \prime}$ longitude west, and average altitude of $90 \mathrm{~m}$. After the performance of the forest inventory, 21 trees were felled, distributed in 7-diameter classes to cover stand heterogeneity. The biomass and organic carbon were determined for: leaves, live branch, dead branch, wood, bark and roots. The estimate of the OC stock in Acacia mearnssi plantations and in its tree compartments can be carried out using mathematical equations. The total carbon stocked in biomass was $29.79 \mathrm{Mg} \mathrm{ha}^{-1}$, distributed as follows: $64 \%$ in wood, $11 \%$ in root, $9 \%$ in bark, $7 \%$ in live branches and $4 \%$ in dead branches and leaves.
\end{abstract}

Keywords: Black wattle, forest plantations and biomass.

\section{INTRODUÇÃO}

Em solos tropicais e subtropicais altamente intemperizados, a matéria orgânica (MO) e a serapilheira têm grande importância para o fornecimento de nutrientes às espécies florestais e constituem-se num componente fundamental da capacidade produtiva (BAYER e MIELNICZUK, 1999). Além disso, é considerada a principal fonte de entrada de carbono orgânico (CO) para o solo, proveniente da deposição de resíduos de origem vegetal e animal resultantes da decomposição parcial pela mesofauna e, posteriormente, pela ação

\footnotetext{
${ }^{1}$ Recebido em 27-11-2007 e aceito para publicação em 23.06.2009.

${ }^{2}$ Fundação Estadual de Pesquisa Agropecuária (FEPAGRO). Boca do Monte, 7 Distrito - Caixa Postal: 346, CEP: 97001970. Santa Maria/RS. <fabio-saidelles@ fepagro.rs.gov.br>.

${ }^{3}$ Departamento de Engenharia Florestal/Centro de Ciências Agrárias. Universidade Federal do Espírito Santo. Alto Universitário, s/n - Guararema. Caixa Postal: 16, CEP: 29500-000, Alegre/ES. <caldeiramv@ @q.cnpq.com.br>.

${ }^{4}$ Departamento de Ciências Florestais/Centro de Ciências Rurais. Universidade Federal de Santa Maria. Av Roraima s/n Camobi, CEP: 97105-900, Santa Marias/RS. <schumacher@ pq.cnpq.br>.

${ }^{5}$ Departamento de Engenharia Florestal/CESNORS/UFSM. BR 386, Km 40, Linha Sete de Setembro, s/n - CEP 98400-000, Frederico Westphalen/RS. <rbalbinot@yahoo.com.br>.
} 
decompositora dos microrganismos. Porém, nesse processo, parte do carbono presente nos resíduos é liberada para a atmosfera como dióxido de carbono $\left(\mathrm{CO}_{2}\right)$, e o restante passa a fazer parte da $\mathrm{MO}$ do solo.

Cabe ressaltar, contudo que a quantidade de resíduos florestais retornados ao solo varia com a espécie florestal. Nesse sentido, Andrade (1997) argumentou que as leguminosas arbóreas (Mimosa caesalpiniifolia, Acacia mangium e Acacia holosericea) têm a capacidade de armazenar quantidades significativas de carbono e nitrogênio nas raízes, enquanto espécies do gênero Casuarina acumulam grandes quantidades de nutrientes na serapilheira e contribuem, de maneira significativa, para aumentar o teor de CO e nitrogênio armazenado no solo (WANG et al., 1991). De acordo com Persson (1979), de 20 a $65 \%$ do CO assimilado pelas plantas são utilizados no crescimento e manutenção de raízes finas, denotando, assim, a importância desse componente da planta na fixação e acúmulo de $\mathrm{CO}$ no solo.

Caldeira et al. (2003), entretanto, verificaram que em florestas plantadas a captura e fixação de carbono ocorreram em maior proporção na madeira do que nos demais componentes da biomassa. Assim, a quantificação do CO torna-se importante, porque durante a existência dessas florestas são imobilizadas quantidades diferenciadas de carbono da atmosfera nos diferentes componentes da planta. Dessa forma, estudos sobre o teor de CO precisam ser feitos a respeito dos diversos tipos de florestas e plantações florestais no Brasil. A limitação desses estudos está na dificuldade de se ter metodologia adequada para determinar, principalmente, a biomassa radicial, além de ser trabalho que envolve grande número de pessoas e recursos (CALDEIRA et al., 2003). Nesse sentido, este estudo teve como objetivos quantificar e estimar o estoque de carbono orgânico estocado em árvores de Acacia mearnsii com 4 anos de idade na Região Sul do Brasil, utilizando equações matemáticas.

\section{MATERIAL E MÉTODOS}

\subsection{Características da área de estudo}

O município de Arroio dos Ratos localiza-se na Depressão Central do Estado do Rio Grande Sul, na microrregião do Vale do Jacuí, limitada ao norte pela encosta do planalto basáltico e ao sul pelo escudo rio-grandense, situada nas coordenadas geográficas: Latitude $30^{\circ} 07^{\prime} 12^{\prime \prime}$ Sul e Longitude $51^{\circ} 57^{\prime} 45^{\prime \prime}$ Oeste de Greenwich, com altitude média de $90 \mathrm{~m} \mathrm{snm}$.

De acordo com a classificação de Köppen, o clima da região é do tipo Cfa, subtropical (MORENO, 1961). A temperatura média do mês de janeiro fica em torno de $24^{\circ} \mathrm{C}$, a do mês de julho em $13^{\circ} \mathrm{C}$ e a temperatura média anual entre $18-19^{\circ} \mathrm{C}$, sendo a temperatura média das máximas no ano de $24^{\circ} \mathrm{C}$ e a das mínimas no ano, de $14{ }^{\circ} \mathrm{C}$. As precipitações pluviais anuais no ano variam de 1.200 a 1.600 mm e são bem distribuídas, ocorrendo de 100 a 120 dias de chuva no ano. A região apresenta, de maio a agosto, $600 \mathrm{~h}$ de frio abaixo de $10{ }^{\circ} \mathrm{C}$ e $200 \mathrm{~h}$ de frio de maio a agosto abaixo de 7 ${ }^{\circ} \mathrm{C}$. A umidade relativa do ar média, radiação solar média e insolação anual total varia, respectivamente, de 75 a $80 \%$, de 325 a 375 cal.cm ${ }^{-2}$.dia ${ }^{-1}$ e de 2.200 a $2.600 \mathrm{~h}$ (INSTITUTODE PESQUISAS AGRONÔMICAS, 1989).

Segundo Embrapa (2006), o solo da área de estudo é classificado como ARGISSOLO VERMELHO Distrófico, típico relevo suave-ondulado.

\subsection{Implantação do povoamento}

O plantio foi realizado em setembro de 1997, numa área de 2.564 ha, estando no momento do estudo com 4 anos de idade. O espaçamento utilizado foi de 3,0 x 1,30 m, tendo como preparo de solo a subsolagem com uma haste a profundidade de 45 $\mathrm{cm}$ e gradagem na linha de plantio. A semeadura foi realizada utilizando-se plantadeira hidráulica de acácianegra (PHA). Em cada cova, foram colocadas oito sementes. Simultaneamente com o plantio, foi realizada a adubação, utilizando-se $40 \mathrm{~g}$ por cova de NPK (02-32-06). Posteriormente, foi realizado o raleio 45 dias após a emergência, mantendo a muda mais central e desenvolvida. Foi feito replantio com mudas (idade de 45 a 50 dias) aproximadamente 40 a 30 dias após a semeadura direta.

\subsection{Inventário florestal da área amostral}

Inicialmente, foi escolhida uma área homogênea quanto às condições de sítio, em que foram demarcadas sete parcelas de formato retangular de $20 \times 30 \mathrm{~m}\left(600 \mathrm{~m}^{2}\right)$. Em cada uma das parcelas, foram medidos os diâmetros à altura do peito (DAP) de todas as árvores com suta e altura (h) de 10\% destas, com aparelho Vertex. 
Tabela 1-Equação de regressão testada para estimar as alturas de Acacia mearnsii De Wil. com 4 anos de idade em Arroio dos Ratos, RS.

Table 1 - Equations used for regression analysis to estimate heights for 4-yearold Acacia mearnsii De Wild. in Arroio dos Ratos, $R S$

\begin{tabular}{ccccc}
\hline Modelo & \multicolumn{2}{c}{ Coeficientes } & $\mathrm{R}_{\mathrm{aj}}{ }^{2}$ & \\
\cline { 2 - 5 } & $\mathrm{b}_{0}$ & $\mathrm{~b}_{1}$ & Syx (\%) \\
\hline $\log \mathrm{h}=\mathrm{b}_{0}+\mathrm{b}_{1} * 1 /$ DAP & 1,378574 & $-2,079563$ & 0,92 & 3,0 \\
\hline
\end{tabular}

Sendo: $\mathrm{h}=$ altura $(\mathrm{m}) ; \log =\log$ aritmo de base $10 ; \mathrm{DAP}=$ diâmetro à altura do peito $(\mathrm{cm})$.

As alturas das árvores que não foram medidas foram estimadas através da equação de relação hipsométrica (h/d), que apresentou os melhores parâmetros de ajuste para a região e para a espécie, na época da realização da pesquisa (Tabela 1).

O baixo erro-padrão e o alto coeficiente de determinação da equação (Tabela 1) indicam bom ajuste dos diâmetros em relação às alturas e tornou-se viável usá-la para estimar as alturas das árvores. O volume total com e sem casca foi obtido com base nas equações propostas por Schneider e Hosokawa (1978), a partir dos dados de DAP e altura do povoamento (Tabela 2 ).

A partir dos dados do inventário foi obtida a distribuição diamétrica, e as árvores foram agrupadas em classes de diâmetro, de modo a abranger as variações ocorridas no povoamento. O número de classes foi calculado pela fórmula de Sturges, descrita por Finger (1992), a qual é expressa por: $\mathrm{K}=1+3,3 * \log \mathrm{n}$, em que: $\mathrm{n}=$ número de observações e K=número de classes. Também foi determinado o intervalo de classes com base na fórmula $h=H / K$, sendo $H=$ amplitude total (DAP máx - DAP min), K = número de classes e $\mathrm{h}=$ intervalo de classe $(\mathrm{cm})$.

Na Figura 1, tem-se a distribuição do número de árvores, por hectare, e também se observa que a maioria delas se encontrava nas classes intermediárias.

\subsection{Biomassa acima do solo}

Para cada classe diamétrica foram selecionadas três árvores, de modo que a maior amplitude dos dados fosse contemplada. Depois de abatidas, as árvores foram medidas e, na sequência, os galhos foram separados do tronco e classificados em vivos (verdes) e mortos (secos). Dos galhos verdes foram separadas todas as folhas. O tronco foi descascado e separado em dois componentes: madeira e casca. Ainda no campo, os componentes (madeira, casca, folhas, galhos vivos e galhos mortos) tiveram seu peso úmido determinado, mediante a pesagem com a utilização de uma balança de gancho.

No campo foram retiradas amostras de todos os componentes das árvores, as quais foram pesadas em balança com precisão de 0,01 g. Para a madeira e casca, com o auxílio de uma motosserra foram retiradas amostras a $50 \%$ da altura total das árvores.

Depois de identificadas, as amostras foram encaminhadas para o Laboratório de Ecologia Florestal da Universidade Federal de Santa Maria, onde foram postas em estufa de circulação de ar, à temperatura de $65^{\circ} \mathrm{C}$, até atingirem peso constante. Estabeleceu-se a

Tabela 2-Equações utilizadas para cálculo do volume total com e sem casca para Acacia mearnsii com 4 anos de idade, em Arroio dos Ratos, RS.

Table 2 - Equations utilized for 4-year-old Acacia mearnsii De Wild. total volume calculation with and without bark in Arroio dos Ratos, RS.

\begin{tabular}{lcr}
\hline \multicolumn{1}{c}{ Modelo } & \multicolumn{2}{c}{ Coeficientes } \\
\cline { 2 - 3 } & $\mathrm{b}_{0}$ & $\mathrm{~b}_{1}$ \\
\hline $\log \mathrm{vcc}=\mathrm{b}_{0}+\mathrm{b}_{1}{ }^{*} \log \left(\mathrm{DAP}^{2} \mathrm{~h}\right)$ & $-4,20076$ & 0,9494568 \\
$\log \mathrm{vsc}=\mathrm{b}_{0}+\mathrm{b}_{1}{ }^{*} \log \left(\mathrm{DAP}^{2} \mathrm{~h}\right)$ & $-4,29654$ & 0,9562276 \\
\hline
\end{tabular}

Sendo: $\mathrm{h}=$ altura $(\mathrm{m}) ; \log =\log$ aritmo de base $10 ; \mathrm{DAP}=$ diâmetro à altura do peito $(\mathrm{cm})$; vsc = volume total sem casca $\left(\mathrm{m}^{3}\right) ; \mathrm{vcc}=$ volume total com casca $\left(\mathrm{m}^{3}\right)$. 


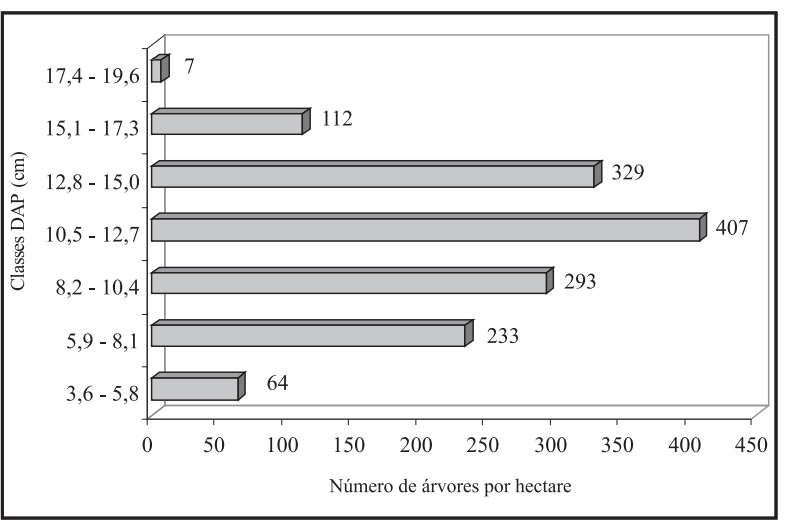

Figura 1 - Número de árvores, por hectare, de Acacia mearrnii De Wild., distribuídas nos intervalos de classes de DAP com 4 anos de idade, em Arroio dos Ratos, RS.

Figure 1-Number of trees per hectare of 4-year-old Acacia mearrnii De Wild., distributed in BHD class intervals in Arroio dos Ratos, $R S$.

relação peso de massa seca/úmida para as amostras, que serviu para a estimativa do peso de matéria seca de massa seca de cada componente da árvore e, com isso, a determinação da biomassa seca.

\subsection{Biomassa abaixo do solo}

Todas as árvores amostradas, ou seja, 21, tiveram suas raízes escavadas com o auxílio de um trator Valmet $1184 \times 2$.

Por meio do uso de bomba de alta pressão Jacto 6.500 (vazão $6 \mathrm{~L} \mathrm{~m}^{-1}$ ), foram submetidas à lavagem, na qual o solo aderido às raízes foi totalmente removido, e todas as raízes com diâmetro acima de $0,50 \mathrm{~cm}$ foram coletadas, bem como determinado o seu peso úmido. O diâmetro das raízes foi determinado através do auxílio de um gabarito, sendo posteriormente levadas ao Laboratório de Ecologia Florestal da Universidade Federal de Santa Maria, onde foram postas em estufa de circulação de ar, à temperatura de $65^{\circ} \mathrm{C}$, até atingirem peso constante. Estabeleceu-se a relação peso seco/úmido para as amostras, a qual serviu para a estimativa dos pesos de matéria seca e, com isso, a determinação da biomassa seca.

\subsection{Relação entre DAP e biomassa arbórea}

A partir dos dados dos componentes da biomassa acima e abaixo do solo e do DAP das 21 árvores amostradas, ajustou-se o modelo de regressão $\left(\log \mathrm{y}=\mathrm{b}_{0}+\mathrm{b}_{1} * \log\right.$ DAP $)$, em que y é a biomassa total (acima e abaixo do solo). Com esse modelo, estimou-se a biomassa dos diferentes componentes das árvores, que não tiveram seu peso determinado dentro da parcela.

Para observar o ajuste e a precisão do modelo, foram escolhidos parâmetros estatísticos: coeficiente de determinação ajustado $\left(\mathrm{R}^{2}{ }_{\text {aj }}\right)$ e erro-padrão da estimativa em percentagem $\left(\mathrm{S}_{\mathrm{yx}} \%\right)$ (SCHNEIDER, 1997).

\subsection{Determinação do teor de CO nos componentes das árvores}

Para a determinação do teor de $\mathrm{CO}$ nos diferentes componentes das árvores de acácia-negra, as amostras foram secas, moídas e submetidas à metodologia descrita por Tedesco et al. (1995) para análises de tecidos vegetais.

\subsection{Relação entre o DAP e o teor de CO}

Com os dados do teor de $\mathrm{CO}\left(\mathrm{g} \mathrm{kg}^{-1}\right)$, obtidos na análise dos tecidos pelo produto com a biomassa de cada componente $(\mathrm{kg})$, estimou-se a quantidade de $\mathrm{CO}$ dos componentes ( $\mathrm{g}$ árvore ${ }^{-1}$ ). Com a variável dendrométrica (DAP) das respectivas árvores amostradas, foi usada uma equação $\left(\log \mathrm{y}=\mathrm{b}_{0}+\mathrm{b}_{1} \log \mathrm{DAP}\right) \mathrm{em}$ cada componente das árvores.

\subsection{Quantidade de CO nos componentes da biomassa por hectare}

A quantidade de $\mathrm{CO}$ por hectare $\left(\mathrm{kg} \mathrm{ha}^{-1}\right)$ foi determinada com base na média do teor de CO $\left(\mathrm{g} \mathrm{kg}^{-1}\right)$ dos componentes das árvores pelo produto com a biomassa $\left(\mathrm{Mg} \mathrm{ha}^{-1}\right)$ dos respectivos componentes.

\section{RESULTADOS E DISCUSSÃO}

\subsection{Equações ajustadas para determinar a quantidade de carbono orgânico}

As equações ajustadas para estimar o $\mathrm{CO}$ por árvore, com base no DAP das mesmas podem ser observadas na Tabela 3. Utilizou-se essa variável dendrométrica, devido ao bom ajuste dos dados expressos pelo alto coeficiente de determinação e 
Tabela 3 -Equações de regressão utilizadas para estimar o estoque de carbono orgânico (g/árvore) contidos nos diferentes componentes das árvores de Acacia mearnsii com 4 anos de idade, em Arroio dos Ratos, RS.

Table 3 - Regression equations utilized to estimate organic carbon stock (g/trees) in different components off 4 -yearold Acacia mearnsii De Wild. trees in Arroio dos Ratos, RS.

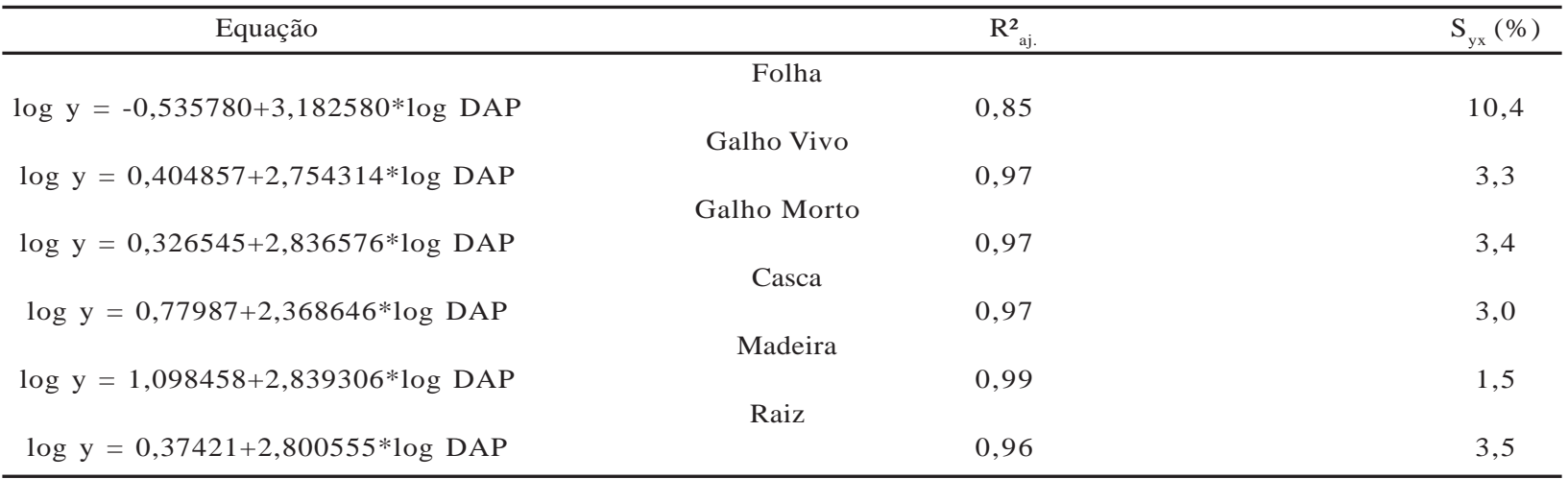

Onde: $\mathrm{R}_{\text {aj. }}^{2}=$ coeficiente de determinação; $\mathrm{S}_{\mathrm{yx}}(\%)=$ erro padrão.

pelo baixo erro-padrão apresentado pela maioria das equações e pela facilidade de obtenção dos dados a campo.

\subsection{Teor de CO nos componentes de acácia-negra}

Os teores de $\mathrm{CO}$ nos diferentes componentes da planta foram distribuídos conforme a Tabela 4, sendo os maiores teores encontrados nas folhas, que diferiram significativamente dos demais componentes da biomassa. Dados semelhantes foram encontrados por Vezzani (1997), Schumacher et al. (2002), Caldeira et al. (2003) e Weber et al. (2003). Caldeira et al. (2003), que também observaram maior teor de carbono nas folhas dos povoamentos de acácia-negra com 4 e 6 anos de idade. Fato esse explicado em função de que, segundo Gonçalves e Mello (2000), os teores dos nutrientes são maiores nas partes mais ativas metabolicamente das plantas, como folhas e brotações, devido aos seus ativos envolvimentos em reações enzimáticas e compostos bioquímicos de transferência de energia e transporte eletrônico, bem como nos diversos processos de fixação de energia em formas orgânicas (VITOUSEK e SANFORD, 1986). Isso não é somente uma característica do carbono orgânico, pois determinados nutrientes, como $\mathrm{P}, \mathrm{K}$ e Mg, também apresentam os maiores teores nas folhas de Acacia mearnsii (CALDEIRA, 1998; PEREIRA et al., 2000; CALDEIRA et al., 2002; BARICHELLO, 2003; SAIDELLES, 2005), bem como micronutrientes (CALDEIRA et al., 2004).
Ao comparar estatisticamente os teores de $\mathrm{CO}$ de seis espécies nativas - Myrsine ferruginea, Ocotea porosa, Mimosa scabrella, Ilex paraguariensis, Symplocos uniflora e Styrax leprosus - da Floresta Ombrófila Mista, na região Sul do Paraná, Weber et al. (2006) também encontraram maiores teores de CO nas folhas, em comparação com outras partes das árvores (casca, fuste, galhos vivos, galhos mortos e miscelânea).

Tabela 4-Teores médios de carbono orgânico $\left(\mathrm{g} \mathrm{kg}^{-1}\right)$, biomassa e estoque de carbono orgânico $\left(\mathrm{Mg} \mathrm{ha}^{-1}\right)$ nos componentes das árvores de Acacia mearnsii De Wild., com 4 anos de idade, em Arroio dos Ratos, RS.

Table 4 - Average levels of organic carbon $\left(\mathrm{g} \mathrm{kg}^{-1}\right)$, biomass and organic carbon stock $\left(M g h a^{-1}\right)$ in components of 4-year-old Acacia mearnsii De Wild. trees in Arroio dos Ratos, RS.

\begin{tabular}{ccccc}
\hline Componente & Média $^{1}$ & & Biomassa $^{3}$ Estoque de CO $^{2}$ \\
\cline { 2 - 2 } \cline { 5 - 5 } $\mathrm{g} \mathrm{kg}^{-1}$ & & \multicolumn{2}{c}{$\mathrm{Mg} \mathrm{ha}^{-1}$} \\
\hline Folha & $455,80 \mathrm{a}^{*}$ & & 2,45 & 1,11 \\
Galho Vivo & $413,99 \mathrm{~b}$ & & 5,30 & 2,20 \\
Galho Morto & $408,78 \mathrm{~b}$ & & 3,35 & 1,37 \\
Casca & $406,80 \mathrm{~b}$ & & 7,09 & 2,89 \\
Madeira $^{4}$ & $421,34 \mathrm{~b}$ & & 46,62 & 19,83 \\
Raiz & $419,20 \mathrm{~b}$ & & 8,12 & 3,39 \\
Total $^{2}$ & & & 71,93 & 29,79 \\
\hline
\end{tabular}

*Médias seguidas pela mesma letra na vertical não diferem a 5\%, pelo teste de Tukey; ${ }^{1}$ Média do teor de $\mathrm{CO}$ por árvore (média das sete árvores); ${ }^{2}$ Total de $\mathrm{CO}$ acumulado por hectare; ${ }^{3}$ Biomassa média por componente por hectare; $\mathrm{e}^{4}$ Média do teor de $\mathrm{CO}$ a $50 \%$ da altura total da árvore (média das sete árvores).

R. Árvore, Viçosa-MG, v.33, n.5, p.907-915, 2009 
A literatura evidencia que o teor dos nutrientes nas folhas das árvores é influenciado por diversos fatores, como: condições de sítio, idade e posição das folhas na copa e época do ano. Nas folhas encontra-se a maior parte das células vivas, que tendem a acumular maiores quantidades de nutrientes em função dos processos de transpiração e fotossíntese (KOZLOWSKI e PALLARDY, 1996; CALDEIRA, 2003).

Estudo realizado com Cryptomeria japonica aos com 28 anos de idade, Weber (2004), verificou que os teores de $\mathrm{CO}$ nos diferentes componentes das árvores em $\mathrm{g} \mathrm{kg}^{-1}$ ficaram alocados: 472,9 nas acículas, 424,9 nos galhos vivos, 423,8 nos galhos mortos, 447,7 na madeira e 432,9 $\mathrm{g} \mathrm{kg}^{-1}$ na casca. Hoppe (2003) determinou para um povoamento de Platanus x acerifolia os teores médios de carbono que ficaram em torno de 444,5 nas folhas, 445,2 nos frutos, 436,3 nos galhos vivos, 424,3 na madeira, 369,6 na casca e $409,5 \mathrm{~g} \mathrm{~kg}^{-1}$ na raiz.

Gayoso e Guerra (2003) observaram para 16 espécies nativas no Chile, maior teor de $\mathrm{CO}$ no componente madeira. A justificativa, segundo os autores, pode estar relacionada a maior quantidade de minerais e lignina contidos neste componente. Os autores encontraram diferença significativa entre o teor de CO nas espécies nativas de coníferas e latifoliadas. Dentro do grupo das espécies latifoliadas, no entanto, não observaram diferença entre caducifolias e perenifólias. Verificaram também diferenças significativas entre o conteúdo e o teor de $\mathrm{CO}$ nos componentes (madeira, folhas, galhos e casca).

\subsection{Estoque de CO na biomassa}

Em ordem decrescente os compartimentos que mais estocaram CO são: madeira do fuste $>$ raiz $>$ casca $>$ galhos vivos $>$ galhos mortos $>$ folhas (Tabela 4 e Figura 2). Os maiores estoques de $\mathrm{CO}$ na madeira e na raiz também foram observados em povoamentos de Pinus taeda com 22 anos de idade (WATZLAWICK et al., 2005), com 14 e 32 anos de idade (WATZLAWICK e CALDEIRA, 2004); em povoamentos de Acacia mearnsii com quatro anos de idade (SCHUMACHER et al., 2002; CALDEIRA et al., 2003), bem como em povoamentos de Acacia mearnsii com oito anos de idade (SCHUMACHER et al., 2002).

Deve-se ressaltar que o estoque de CO nos diferentes componentes deste estudo, comparado com outros trabalhos realizados com a mesma espécie, apresenta

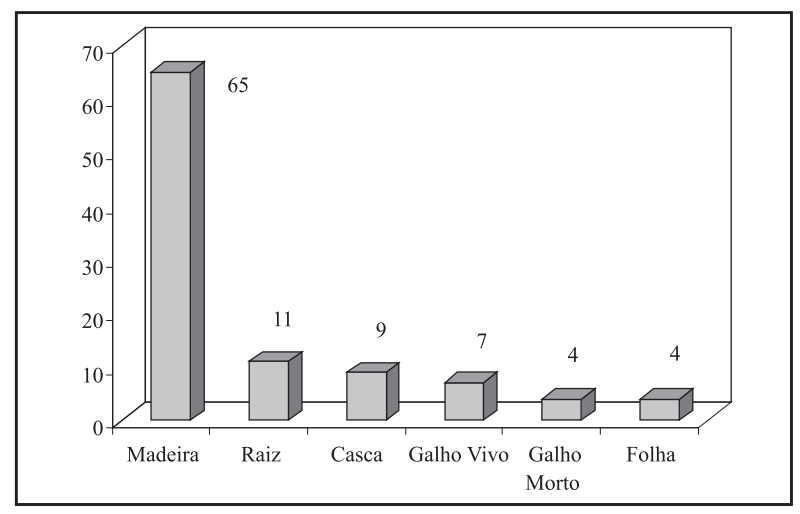

Figura 2-Percentagem de carbono nos diferentes componentes da biomassa, por hectare, em árvores de Acacia mearnsii De Wild. com 4 anos de idade, em Arroio dos Ratos, RS.

Figure 2-Percentage of carbon in different biomass components, per hectare, 4- year-old Acacia mearnsii De Wild.

valores diferentes em razão provavelmente, de fatores ambientais e,ou, inerentes à planta (SPURR e BARNES, 1986), condições edafoclimáticas do sítio (HAAG, 1985; SCHUMACHER，1995), idade (VALERI, 1988; WATZLAWICK, 2003), características ecofisiológicas de cada espécie (SCHUMACHER, 1995; CALDEIRA, 2003) e densidade de indivíduos (VALERI, 1988; WATZLAWICK et al., 2002; WATZLAWICK, 2003), bem como diferentes metodologias utilizadas para ser realizado o levantamento (WATZLAWICK et al., 2002; CALDEIRA, 2003; WATZLAWICK, 2003).

A Figura 2 mostra a distribuição, em percentagem, do CO acumulado nos diferentes componentes da biomassa por hectare de Acacia mearnsii. Para a mesma espécie com quatro anos de idade, Caldeira et al. (2003) chegaram a resultados muito parecidos, pois a percentagem de carbono por hectare nas folhas, galhos mortos, galhos vivos, casca, madeira e raiz foi de 4 , $3,10,8,62$ e $12 \%$, respectivamente. Entretanto, com seis anos de idade, a distribuição foi de $6 \%$ (folhas), $2 \%$ (galhos mortos), 11\% (galhos vivos), $5 \%$ (casca), $66 \%$ (madeira) e $9 \%$ (raiz)

Para a mesma espécie com 4 anos de idade, Caldeira et al. (2003) chegaram a resultados muito parecidos, pois a percentagem de carbono por hectare nas folhas, galhos mortos, galhos vivos, casca, madeira e raiz foi de 4, 3 , $10,8,62$ e $12 \%$, respectivamente. Entretanto, com 6 anos de idade, a distribuição foi de $6 \%$ (folhas), $2 \%$ (galhos mortos), $11 \%$ (galhos vivos), $5 \%$ (casca), $66 \%$ (madeira) e $9 \%$ (raiz). 


\section{CONCLUSÕES}

O teor de CO nas folhas de Acacia mearnssi difere dos demais compartimentos, mostrando-se superior.

Plantações de Acacia mearnssi aos 4 anos de idade fixam até $27,9 \mathrm{Mg} \mathrm{C}^{-1}$ e concentram $65 \%$ dele na madeira.

\section{REFERÊNCIAS}

ANDRADE, A. G. Ciclagem de nutrientes e arquitetura radicular de leguminosas arbóreas de interesse para revegetação de solos degradados e estabilização de encostas. 1997. 178f. Tese (Doutorado em Ciência do Solo) Universidade Federal Rural do Rio de Janeiro, Seropédica, 1997.

BARICHELLO, L. Quantificação da biomassa e dos nutrientes em floresta de Acacia mearnii De Wild. na região sul do Brasil. 2003. 58f. Dissertação (Mestrado em Engenharia Florestal) - Universidade Federal de Santa Maria, Santa Maria, 2003.

BAYER, C.; MIELNICZUK, J. Dinâmica e função da matéria orgânica. In: SANTOS, G. A.; CAMARGO, F. A. O. (Eds) Fundamentos da matéria orgânica do solo: ecossistemas tropicais e subtropicais. Porto Alegre: Gênesis, 1999. p.9-26.

CALDEIRA, M. V. W. Determinação de biomassa e nutrientes em uma Floresta Ombrófila Mista Montana em General Carneiro, Paraná. Curitiba, 2003. 176f. Tese (Doutorado em Ciências Florestais) - Setor de Ciências Agrárias, Universidade Federal do Paraná, Curitiba, 2003.

CALDEIRA, M. V. W. Quantificação da biomassa e do conteúdo de nutrientes em diferentes procedências de Acácianegra (Acacia mearnsii De wild.). 1998. 966 . Dissertação (Mestrado em Engenharia Florestal) Universidade Federal de Santa Maria, Santa Maria, 1998.

CALDEIRA, M. V. W.; RONDON NETO, R. M.; SCHUMACHER, M. V. Avaliação da eficiência nutricional de três procedências australianas de acácia-negra (Acacia mearnsii De Wild.).

Revista Árvore, v.26, n.5, p.615-620, 2002.
CALDEIRA, M. V. W.; RONDON NETO, R. M.; SCHUMACHER, M. V. Eficiência do uso de micronutrientes e sódio em três procedências de acácia-negra (Acacia mearnsii De Wild.). Revista Ârvore, v.28, n.1, p.39-47, 2004.

CALDEIRA, M. V. W. et al. Determinação de carbono orgânico em povoamentos de Acacia mearnsii De Wild. plantados no Rio Grande do Sul. Revista Acadêmica: Ciências Agrárias e Ambientais, v.1, n.2, p.47-54, 2003.

EMPRESA BRASILEIRA DE PESQUISA AGROPECÚARIA - EMBRAPA. Sistema brasileiro de classificação de solos. 2.ed. Rio de Janeiro: Embrapa Solos, 2006. 306p.

FINGER, C. A. G. Fundamentos de biometria florestal. Santa Maria: UFSM/ CEPEF/FATEC, 1992.201p.

GAYOSO, J.; GUERRA, J. Contenido de carbono en la biomassa aérea de bosques nativos en Chile. In: Medición de la capacidad de captura de carbono en bosques de Chile y promoción en el mercado mundial. Valdivia, Universidad Austral de Chile, 2003. 8p.

GONÇALVES, J. L. M.; MELLO, S. L. M. O sistema radicular das árvores. In: GONÇALVES, J. L. M.; BENEDETTI, V. (Eds.) Nutrição e fertilização florestal. Piracicaba: ESALQ/ USP, 2000. p.221-267.

HAAG, H. P. Ciclagem de nutrientes em florestas tropicais. Campinas: Fundação Cargil, 1985. 144p.

HOPPE, J. M. Biomassa e nutrientes em Platanus $x$ acerifolia (Aiton) Willd. estabelecido no município de Dom Feliciano-RS. 2003. 143f. Tese (Doutorado em Engenharia Florestal) - Universidade Federal de Santa Maria, Santa Maria, 2003.

INSTITUTO DE PESQUISAS AGRONÔMICAS IPAGRO. Atlas agroclimático do Estado do Rio Grande do Sul. Porto Alegre: 1989. 3 v. 326 p.

KOZLOWSKI, T. T.; PALLARDY, S. G. Physiological of woody. 2.ed. San Diego: Academic, 1996. 432p.

R. Árvore, Viçosa-MG, v.33, n.5, p.907-915, 2009 
MOREno, J. A. Clima do Rio Grande do Sul. Porto Alegre: Secretaria da Agricultura, 1961. 42p.

PEREIRA, J. C. et al. Estimativa do conteúdo de nutrientes em um povoamento de Acacia mearnsii De Wild. no Rio Grande do Sul - Brasil. Revista Árvore, v.24, n.2, p.193-199, 2000.

PERSSON, H. Fine root production, mortality, and decomposition in forest ecosystems. In:

Vegetatio, v.41, p.101-109, 1979.

SAIDELLES, F. L. F. Determinação da biomassa e altura de amostragem para a quantificação de nutrientes em Acacia mearnsii De Wild. 2005. 97f. Tese (Doutorado em Engenharia Florestal) - Universidade Federal de Santa Maria, Santa Maria, 2005.

SCHNEIDER, P. R. Análise de regressão aplicada à engenharia florestal. Santa Maria: CEPEF, 1997.217p.

SCHNEIDER, P. R.; HOSOKAWA, R. T. Estudo de equações volumétricas para Quadros de volume com e sem casca para Acácia Negra (Acacia mearnsii De Wild). In: CONGRESSO FLORESTAL BRASILEIRO, 3., 1978, Manaus. Anais... Manaus: 1978. p.90-95.

SCHUMACHER, M. V. Naehrstoffkreislauf in verschiedenen Bestaeden von Eucalyptus saligna (Smith), Eucalyptus dunnii (Maiden) und Eucalyptus globulus (Labillardière) in Rio Grande do Sul, Brasilien. 1995. $167 \mathrm{f}$. Tese (Doutorado em Ecologia e Nutrição Florestal) Universitäet für Bodenkultur, Wien, 1995.

SCHUMACHER, M. V. et al. Estoque de carbono em florestas de Pinus taeda L. e Acacia mearnsii De Wild. Estado do Rio Grande do Sul. In: SANQUETTA, C. R. et al. (Eds.). As florestas e o carbono. Curitiba: 2002. p.141-152.

\section{SPURR, S. H. \& BARNES, B. V. Ecologia} forestal. Mexico: 1986. 690p.

TEDESCO, M. J. et al. Análises de solos, plantas e outros materiais. 2.ed. Porto Alegre: Universidade Federal do Rio Grande do Sul, 1995. (Boletim Técnico, 5).

R. Árvore, Viçosa-MG, v.33, n.5, p.907-915, 2009
VALERI, S. V. Exportação de biomassa e nutrientes de povoamentos de Pinus taeda L, desbastados em diferentes idades. 1988. 164f. Tese (Doutorado em Ciências Florestais) - Universidade Federal do Paraná, Curitiba, 1988.

VEZZANI, F. M. Aspectos nutricionais de povoamentos puros e misto de Eucalyptus saligna (Smith) Acacia mearnsii (De Wild.). 1997. 97f. Dissertação (Mestrado em Ciência do Solo) - Universidade Federal do Rio Grande do Sul, Porto Alegre, 1997.

VITOUSEK, P. M.; SANFORD, R. L. Nutrient cycling in moist tropical forest. Annual Review of Ecology and Systematics, v.17, p.137-167, 1986.

WANG, D. et al. Comparison of nutrient use efficiency and biomass production in five tropical tree taxa. Forest Ecology and Management, v.46, n.1, p.1-21, 1991.

WATZLAWICK, L. F. Estimativa de biomassa e carbono em Floresta Ombrófila Mista e plantações florestais a partir de dados de imagens do satélite IKONOS II. 2003. 120f. Tese (Doutorado em Ciências Florestais) Universidade Federal do Paraná, Curitiba, 2003.

WATZLAWICK, L. F.; CALDEIRA, M. V. W. Estimativa de biomassa e carbono orgânico em povoamentos de Pinus taeda L. com diferentes idades. Biomassa \& Energia, v.1, p.371380, 2004.

WATZLAWICK, L. F. et al. Fixação de carbono em Floresta Ombrófila Mista em diferentes estágios de regeneração. In: SANQUETTA, C. R. et al., (Eds.) As florestas e o carbono. Curitiba: 2002. p.153-173.

WATZLAWICK, L. F.; SANQUETTA, C. R.; CALDEIRA, M. V. W. Estoque de carbono orgânico e biomassa em Pinus taeda L.

Biomassa \& Energia, v.2, n.1, p.7-17, 2005. 
WEBER, C. Biomassa e nutrientes em um povoamento de Cryptomeria japonica (L.F.) D. Don., no município de Encruzilhada do Sul-Rio Grande do

Sul. 2004. 36f. Relatório de Estágio

Supervisionado em Engenharia Florestal -

Universidade Federal de Santa Maria, Santa

Maria, 2004.
WEBER, K. S. et al. Teores de carbono orgânico de seis espécies naturais do ecossistema da Floresta Ombrófila Mista. Ambiência, v.2, n.2, p.167-177, 2006.

WEBER, K. S. et al. Variação nos teores de carbono orgânico em povoamentos de Araucaria angustifolia (Bert.) O. Ktze. Brasil Florestal, n.76, p.23-28, 2003. 